\title{
Lipid and Glucose Metabolism of Broilers (Gallus gallus domesticus) Experimentally Infected with Eimeria acervulina Tyzzer, 1929 Oocysts
}

\section{Author(s)}

Freitas FLC

Almeida $\mathrm{KS}^{2}$

Machado RZ

Machado $\mathrm{CR}^{3}$

Departamento de Patologia Animal da Universidade Estadual Paulista (UNESP), Campus de Jaboticabal-SP, São Paulo, Brazil.

2 Escola de Medicina Veterinária e Zootecnia da Universidade Federal do Tocantins (EMVZ - UFT), Campus de Araguaina, Tocantins, Brazil

3 Departament of Animal Morphology and Physiology (UNESP), Campus de JaboticabalSP, São Paulo, Brazil.

\section{Mail Address}

Fagner LC Freitas

Departamento de Patologia Animal

Via de acesso Prof. Paulo Donato Castellane, $\mathrm{s} / \mathrm{n}$

14.884-900. Jaboticabal, SP, Brazil.

Fone (fax): (16) 3209-2646

E-mail: fagner@fcav.unesp.br

\section{Keywords}

Broilers, Eimeria acervulina, Fatty acids, glucose, total cholesterol, triglycerides.

Study funded by Fundação de Amparo a Pesquisa do Estado de São Paulo

\section{ABSTRACT}

Lipid and glucose metabolism of 76 ten-day-old Cobb male broilers, experimentally infected with Eimeria acervulina, was studied for 30 days. Birds were distributed in 2 groups: one infected with $1 \times 10^{6} \mathrm{E}$. acervulina sporulated oocysts, and the other inoculated with distilled water. Pathological e biochemical liver changes were assessed, as well as plasma glucose concentrations and total cholesterol, HDL, LDL, VLDL, fatty-acid, and triglyceride levels in the serum. The infected broilers presented hypoglycemia associated with a reduction in liver glycogen. In addition, these birds developed fatty liver, and there were changes in all lipid classes in the serum. Lipid and glucose metabolism was dramatically changed in broilers experimentally infected with $1 \times 10^{6} \mathrm{E}$. acervulina oocysts.

\section{INTRODUCTION}

Eimeriosis is a severe animal health problem, considering its high incidence and the several organic changes it may cause. Kessler et al. (1979) asserted that this disease hinder poultry production development, as it is easily transmissible, and expensive to control. The growing meat demand in the international and domestic markets promoted an increase in drug and vaccine consumption in poultry farms with the aim of reducing mortality. However, the misuse of anticoccidial drugs, associated with health management failures, contributed to the emergence of resistant strains, resulting in the permanence of this parasite in the farms.

Among the Eimeria species that parasite broilers, Eimeria acervulina is noteworthy as it affects the intestinal absorption of nutrients required for broiler growth and metabolism (Allen, 1988; Bensadoun e Rothfeld, 1972). The lesions caused by this parasite disturb nutrient absorption, triggering several changes in carbohydrate, lipid, protein, and macroand trace mineral metabolism (Witlock and Ruff, 1977). Both the mechanisms involved in these changes and the time they occur after infection are not fully elucidated.

In Brazil, there are no published studies on metabolic changes of broilers infected with $E$. acervulina, and studies carried out abroad and in previous decades used slow-growing broilers, which makes their results difficult to extrapolate to modern, fast-growing broiler genetic lines.

The present study aimed at evaluating lipid and glucose metabolism of broilers experimentally infected with $E$. acervulina oocysts.

\section{MATERIAL AND METHODS}

In this experiment, 76 ten-day-old male Cobb broilers, derived from the hatchery of the company Frango Sertanejo S.A, located in Guapiaçú, 
São Paulo, Brazil, were used. Birds were group based on body weight, and randomly distributed in two experimental groups. Group A birds were inoculated with $1 \mathrm{~mL}$ of a solution containing $1 \times 10^{6}$ E. acervulina sporulated oocysts, and group $C$ birds were used as controls, and were inoculated with $1 \mathrm{~mL}$ distilled water. Each group consisted of 38 birds. The inoculating dose was based on the anticoccidial drug assessment guide written by Woldsworth et al. (2004). Birds were manually restrained and orally inoculated with the aid of an automatic pipette.

Each group was housed in $1 \mathrm{~m}$ long $\mathrm{x} 2 \mathrm{~m}$ wide $\mathrm{x}$ $1,5 \mathrm{~m}$ high metal cages with iron mesh floors. Trough feeders and drinkers, containing balanced feed with no anticoccidial drugs and clean water, respectively, were cleaned and disinfected every $12 \mathrm{~h}$ in order to prevent infection. A two-phase feeding regime, using a corn and soybean meal feed, was adopted: starter ( 1 to 21 days of age) and grower (22 to 30 days of age). Feeds were formulated according to standards established by the NRC (1998), and fed ad libitum.

Blood was collected, with no previous fasting, directly from the heart using disposable syringes and needles. One $\mathrm{ml}$ of blood was placed in sterile test tubes containing ethylenediaminetetraacetic acid sodium fluoride (EDTA - fluoride), and $4 \mathrm{ml}$ in sterile test tubes with no anti-clotting agents to obtain plasma and serum, respectively, after centrifugation. The test tubes were submitted to the Research Lab of the Clinical Department of the School of Agriculture and Veterinary Sciences of Universidade Estadual Paulista, Jaboticabal campus, for biochemical analysis. Plasma glucose was determined by enzymatic test (Hexokinase - Labtest Sistemas de Diagnósticos Ltda - Belo Horizonte/MG) carried out immediately after collection. Serum lipids were measured as follows: lipoprotein triacylglycerols were quantified using the method proposed by Nagele et al. (1984); total cholesterol was quantified according to the method proposed by Alain et al. (1974) and modified by Good et al. (1966); and HDL cholesterol using commercial kits (Labtest Sistemas de Diagnósticos Ltda - Belo Horizonte/MG). LDL cholesterol was calculated according to the formula: $\mathrm{LDL}=$ total cholesterol - HDL - VLDL. Free fatty acids were measured by the method of Stuart (1986) using a commercial kit (Wako Chemicals NEFA Company, Code 994 - 75409E, Germany). Total liver lipids were gravimetrically determined after extraction with chloroform-methanol $(2: 1, v / v)$ as described by Bligh \& Dyer (1959). Liver glycogen was measured using the technique described by Carrol et al. (1956).
Glucose, total cholesterol, HDL, LDL, and VLDL cholesterol, and triacylglycerols were measured in the periods of 0 to $15,20,25$, and 30 dpi (days postinfection); fatty acid levels were obtained in the periods of 0 to $10,15,20,25$, and $30 \mathrm{dpi}$; liver glycogen and total lipids were determined in the periods of 0 to 15 , 20 , and $30 \mathrm{dpi}$. In order to check these measurements, blood samples were collected from two birds per group. Birds were sacrificed by neck dislocation, and their livers were removed for chemical and pathological analyses. For histopathology, liver samples were placed in buffered formalin at 10\%, and later embedded in paraffin, cut in a microtome, placed in slides, and stained with hematoxylin-eosin ( $\mathrm{HE})$.

Data were analyzed using the non-parametric statistical test of Wilcoxon at 5\% significance level.

\section{RESULTS AND DISCUSSION}

The infected birds presented hypoglycemia, which remained during most of the experimental period ( $p<$ $0,05)$ (Figure 1). The low levels of plasma glucose possibly activated the pancreatic secretion of glucagon, which mobilized liver glycogen to try to reinstate glucose homeostasis, as suggested by to the study carried out of Allen \& Mcmurtry (1984) who observed high glucagon levels during the first week after the infection with $E$. acervulina oocysts. This process is easier to observe during the first week after infection, as glucose levels followed liver glycogen breakdown $(p<0,05)$ (Figure 2). According to Freeman (1970), anorexia and intestinal tract inflammation inhibit glucose absorption, using up liver glycogen reserves, and in severe infections, hypoglycemia is due to inhibition of liver glycogenolysis. Figures 1 and 2 also show that, on certain days, the glucose levels of the infected birds were similar to those of the control group. In addition to glycogen breakdown with subsequent release of glucose, other factors possibly contributed to this. Firstly, not all regions of the small intestine were damaged, i.e., it is possible that there was compensatory absorption by segments that were not affected by the parasite. Secondly, segments of the distal jejunum and ileum (areas not as affected by the infection) may have healed, making absorption return to normal levels.

On 1, 2, and 3 days post-infection (dpi), total liver lipid levels of the infected broilers decreased, and then returned to normal levels. However, on $8 \mathrm{dpi}$, there was a dramatic increase $(p<0,05)$ (Figure 3 ) due to the onset of liver steatosis (fatty liver), which continued 
until the end of the experimental period (Figure 4a). The histopathological exam of the liver revealed multifocal inflammatory infiltrates and the presence of intra-cytoplasmic lipids with homogenous distribution (Figure 4b).

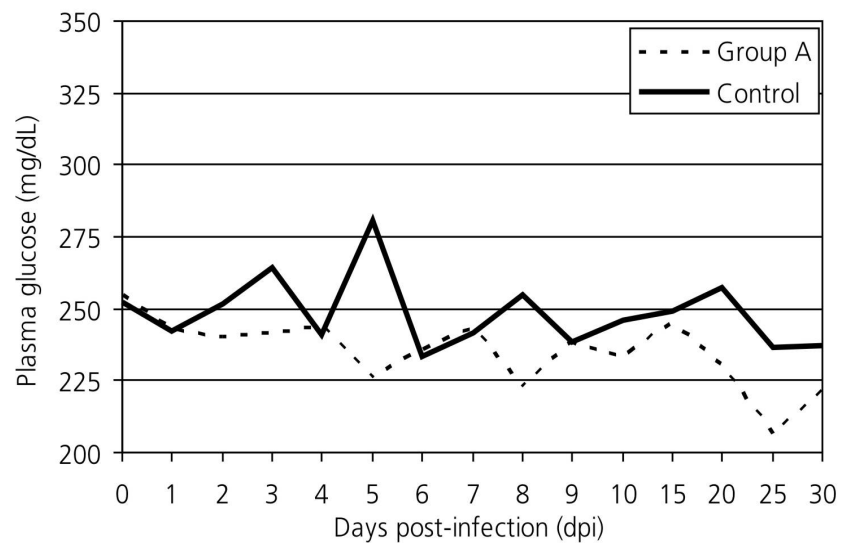

Figure 1- Plasma glucose levels of broilers (Gallus gallus domesticus) experimentally infected with $1 \times 10^{6} \mathrm{E}$. acervulina oocysts.

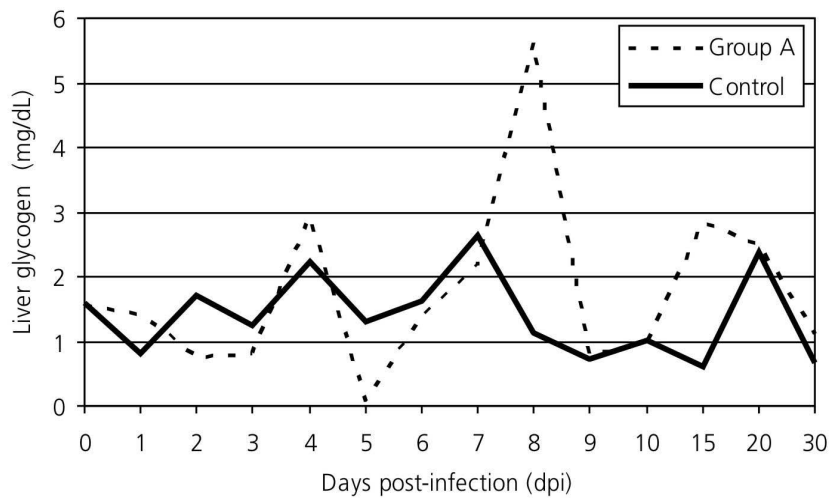

Figure 2 - Liver glycogen levels of broilers (Gallus gallus domesticus) experimentally infected with $1 \times 10^{6} \mathrm{E}$. acervulina oocysts.

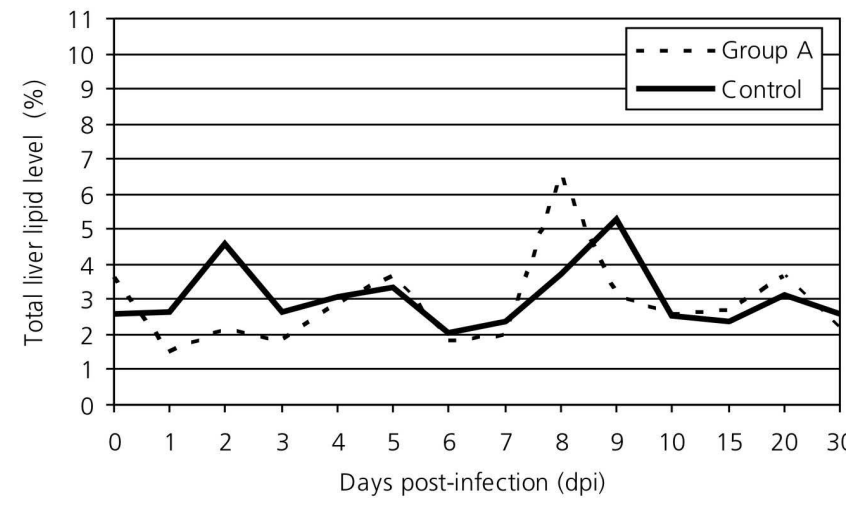

Figure 3 - Total liver lipid levels of broilers (Gallus gallus domesticus) experimentally infected with $1 \times 10^{6} \mathrm{E}$. acervulina oocysts.

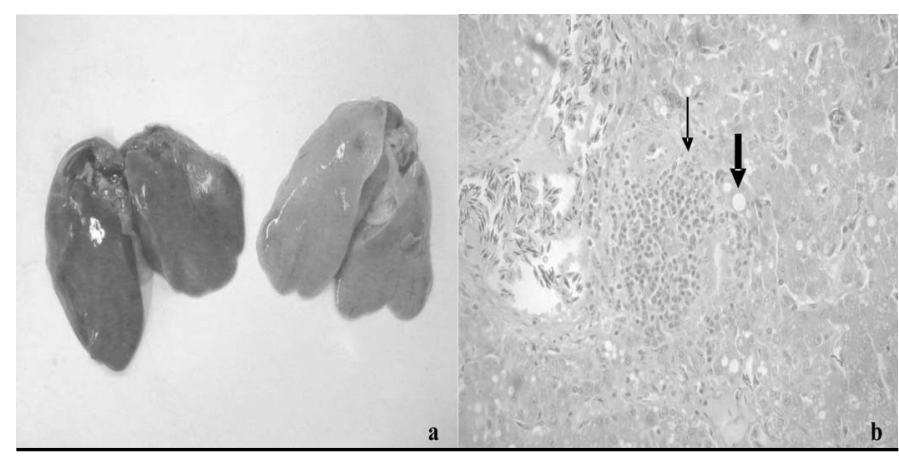

Figure 4 - Gross and microscopic pathological changes observed in the liver of broilers infected with $1 \times 10^{6}$ Eimeria acervulina oocysts. a) Normal liver of control group (left) and yellowish color, characteristic of fatty liver (right). b) Presence of inflammatory infiltrate (thin arrow) and intra-cytoplasmic lipid droplets (thick arrow).

Liver steatosis occurs whenever an agent interferes in the cell metabolism of fatty acids, increasing their synthesis or impairing their utilization, transport, or excretion. This is relevant as in birds $70 \%$ of fatty acid synthesis occurs in the liver, whereas the adipose tissue is the main site of fat synthesis in most other domestic animal species (Machado, 2002). E. acervulina caused reduction in serum fatty acid levels in the first week post-infection, but these returned to normal values on $8 \mathrm{dpi}$, possibly due to the increase of fatty acid synthesis in the liver $(p<0.05)$ (Figure 5$)$, as it was simultaneous to the onset of steatosis. Under normal conditions, the fatty acids absorbed by the intestine are removed from the blood stream by hepatocytes - which are also able to synthesize them - and destined to the synthesis of cholesterol and its esthers; of complex lipids, such as phospholipids and sphingolipids; and of triacylglycerols (Bensadoun \& Rothfeld, 1972). Total cholesterol levels were reduced during the entire experimental period $(p<0.05)$ (Figure 6$)$, possibly due to failure in its synthesis by the liver and intestine, which also synthesize cholesterol (Machado, 2002) and was damaged by $E$. acervulina. As cholesterol is an important component of other molecules, it is possible that its reduction caused by parasitism affects the synthesis of steroid hormones, vitamin D and bile salts. Phospholipid levels were not evaluated in the present experiment, but in the study of Allen (1988) these lipids were reduced in broilers infected with $E$. acervulina during the acute phase of infection. Triacylglycerol levels decreased during the first week, and as the fatty acids, their serum concentration increased on $8 \mathrm{dpi}$ $(p<0.05)$ (Figure 7).

Another factor that may have contributed to lipid metabolism disorder in the present experiment was the clinical anemia presented by the infected birds 
during the first two weeks post-infection. E. acervulina infection causes mild to moderate tissue hypoxia, depending on the infecting dose (Freitas et al., 2006). Tissue hypoxia causes ATP reduction, which in association with the lack of nitrogen factors, reduces the utilization of triacylglycerols or fatty acids for the synthesis of more complex lipids. According to Pereira (2004), steatosis is caused by an increase in fatty acid synthesis from acetyl-CoA excess, which results from its reduced oxidation in the citric acid cycle. These fatty acids combine with a large amount of $\alpha$-glycerol phosphate (derived from accelerated glycolysis due to the reduction in ATP synthesis), and form triacylglycerols, which accumulate in the cytoplasm of hepatocytes.

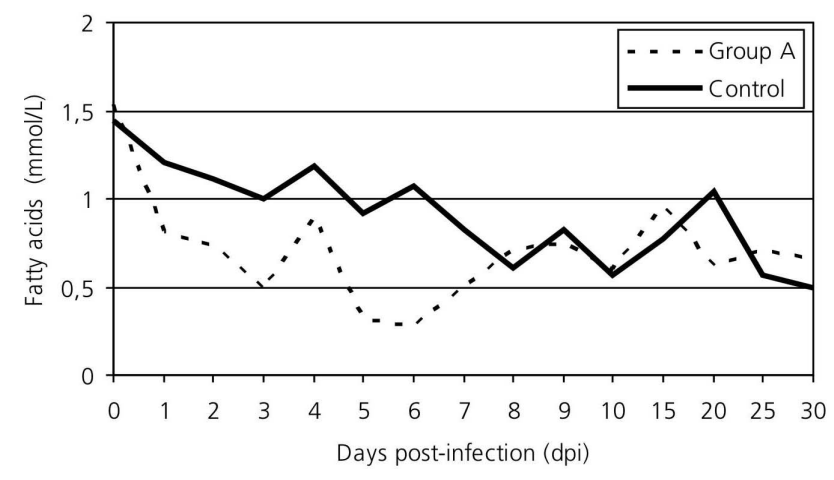

Figure 5 - Serum fatty acid levels of broilers (Gallus gallus domesticus) experimentally infected with $1 \times 10^{6} \mathrm{E}$. acervulina oocysts.

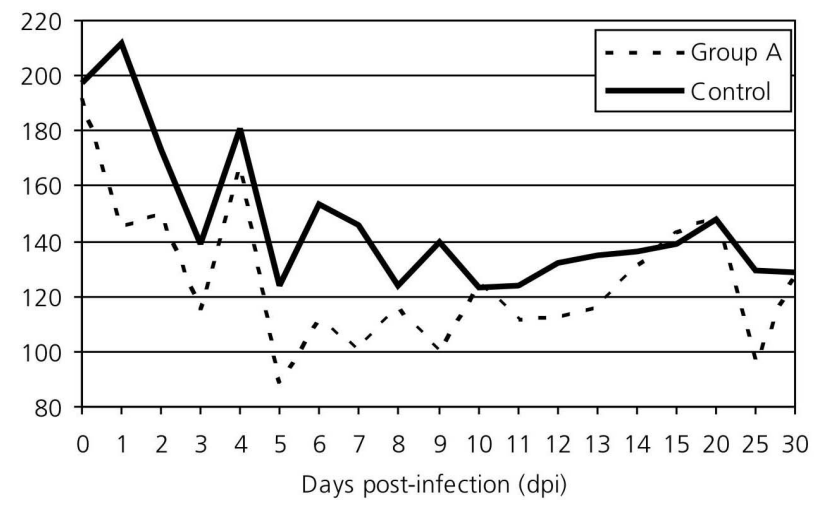

Figure 6 - Total serum cholesterol levels of broilers (Gallus gallus domesticus) experimentally infected with $1 \times 10^{6} \mathrm{E}$. acervulina oocysts.

Birds infected with $E$. acervulina have severe intestinal inflammatory reaction with catarrhal exudation, resulting in epithelial sloughing with intestinal villi loss and atrophy (Kawazoe, 2000). These lesions interfere in the host's nutritional status due to the competition for nutrients by the invading microorganism, nutrient mobilization for defense mechanisms, and impaired nutrient digestion and absorption (Colnago, 1999). Malnutrition or lack of protein leads to the deficiency of lipotropic factors, which are essential for the production of phospholipids, and reduced apolipoprotein synthesis, decreasing lipoprotein synthesis and triacylglycerol excretion (Schaefer et al., 1978). Associated with functional changes of the cell cytoskeleton, these factors may disturb the movement and the fusion of cell vesicles that contain lipoproteins with the plasmatic membrane of the hepatocytes.

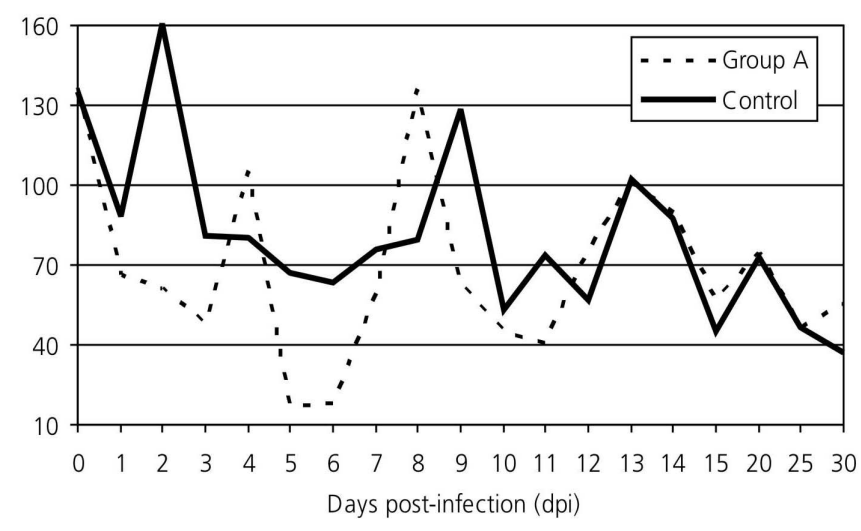

Figure 7 - Serum triclycerid levels of broilers (Gallus gallus domesticus) experimentally infected with $1 \times 10^{6}$ E. acervulina oocysts.

Macari \& Luquetti (2002) asserted that liver damage reduce lipid and protein synthesis. Another factor may have also contributed for the observed fat deposition in the liver. Yun et al. (2000) reported high serum cytokine levels in broilers infected with Eimeria spp. studies carried out with guinea pigs and humans show that high cytokine levels inhibit lipoprotein lipase and stimulate lipid absorption by the liver, resulting in liver steatosis; however, there are no studies that evidence a direct relation between cytokines, lipoprotein lipase, and fat deposition in animals infected with Eimeria species that parasite broilers (Barter, 2005; Esteve et al., 2005).

In the present study, high-density lipoproteins (HDL), low-density lipoproteins (LDL), and very low-density lipoproteins (VLDL) bound to cholesterol were reduced during most of the experimental period $(p<0,05)$. Glucagon also inhibits VLDL synthesis (Tarlow et al., 1977; Allen \& McMurtry, 1984; Allen, 1988), which, in association with nutrient malabsorption and liver changes, was possibly responsible for the low levels of this lipoprotein bound to cholesterol. The LDL fraction is considered as a derivative of VLDL (Schaefer et al., 1978), and its primary functions are to transport 
cholesterol to peripheral tissues and to regulate the synthesis of new cholesterol molecules at these sites (Goldstein \& Brown, 1975). LDL was probably reduced due to a decrease in lipoprotein lipase function or in VLDL synthesis. HDL has a different function, capturing cholesterol released in the plasma by dead cells and membrane turnover, and transporting throughout the body (Schaefer et al., 1978). HDL binds to the cholesterol released by the peripheral tissues and esterifies it, transferring esters to the liver or tissues that use cholesterol to synthesize steroid hormones (Sampietro et al., 2005).

Allen (1988) studied the metabolic effects of $E$. acervulina in poultry and observed, between 4 and 8 dpi, a reduction in plasma lipid and lipoprotein levels, with the lowest levels between 4 and $5 \mathrm{dpi}$, when, according to Witlock \& Ruff (1977), this parasite severely damages duodenal mucosa villi and epithelium. In that study, Allen (1988) also verified that the period between 4 and $6 \mathrm{dpi}$ is associated to anorexia, nutrient malabsorption, influencing total plasma lipid concentrations. Yvore (1978), studying the lipid metabolism of birds infected with E. acervulina, observed a decrease in plasma carotenoid levels during the acute phase of infection, and Allen (1988) found a reduced HDL levels in birds infected by the same parasite.

\section{CONCLUSION}

The intestinal lesions caused by $E$. acervulina infection had a dramatic effect on lipid and glucose metabolism, as shown by the reduction of plasma glucose levels and of all serum lipids, as well as fat deposition in the liver. This evidences the damaging effect of the infection on broiler nutrient absorption and digestion, resulting in severe economic losses for broilers producers.

\section{REFERENCES}

Allain CA, Poon LS, Chan CSG, Richmond W, Fu PC. Enzymatic determination of total serum-cholesterol. Clinical Chemistry 1974; 20(4):470-475.

Allen PC. The effect of Eimeria acervulina infection on plasma lipids and lipoproteins in young broiler chicks. Veterinary Parasitology 1988; 30(1):17-30.

Allen PC, Mcmurtry JP. Changes in pancreatic hormones associated with coccidiosis. Poultry Science 1984; 63(6):1129-1135.

Barter P. The inflammation: lipoprotein cycle. Atherosclerosis 2005; $6(1): 15-20$
Bensadoun A, Rothfeld A. The form of absorption of lipids in the chicken, Gallus domesticus. Proceedings of the Society for Experimental Biology and Medicine 1972; 141(1):814-817.

Bligh EJ, Dyer NJ. Rapid method of total lipid extract purification. Canada Journal of Biochemistry and Physiology 1959; 37(1):911917.

Carrol NV, Longley RW, Roe JH. The determination of glycogen in liver and muscle by use of anthrone reagent. Journal of Biological Chemistry 1956; 220(1):583-593.

Colnago GLA. Coccidiose como doença nutricional. Simpósio Internacional De Cocidiose; 1999; Foz do Iguaçu, Paraná. Brasil. p. 35-44.

Esteve E, Ricart W, Real JM. Dyslipidemia and inflammation: an evolutionary conserved mechanism. Clinical Nutrition 2005; 24(1):16-31.

Freeman BM. Carbohydrate stores in chickens infected with Eimeria tenella. Parasitology 1970; 61(1):245-251.

Freitas FLC, Almeida KS, Tebaldi JH, Machado RZ, Machado CR. Alterações hematológicas em frangos de corte (Gallus gallus domesticus) infectados experimentalmente com Eimeria acervulina Tyzzer, 1929. Revistada Universidade Rural, Série Ciências da Vida 2006; 26(1):181-182.

Goldstein JL, Bronw MS. Familial hypercholesterolemia: a genetic regulatory defect in cholesterol metabolism. American Journal Medicine 1975; 58(1):147-150.

Good NE, Winget GD, Winter W, Connoly TN, Izawa S, Singh RMM. Hydrogen ion buffers for biological research. Biochemistry 1966; 5(2):467.

Holdsworth PA, Conway DP, Mckenzie ME, Dayton AD, Chapman HD, Mathis GF, Skinner JT, Mundt HC, Williams RB. World Association for the Advancement of Veterinary Parasitology (WAAVP) guidelines for evaluating the efficacy of anticoccidial drugs in chickens and turkeys. Veterinary Parasitology 2004; 121(1):189212.

Kawazoe U. Coccidiose. In: Berchieri Júnior A, Macari M, editor. Doenças das aves. Campinas: FACTA; 2000. 800p.

Kessler RH, Silva NRS, Hoffmann RT, Wagner EM. Ocorrência de Eimeria acervulina (TYZZER, 1929) em Gallus gallus domesticus no Rio Grande do Sul. Arquivos da Faculdade de Veterinária da Universidade Federal do Rio Grande do Sul 1979; 7(1):105-119.

Macari M, Luquetti BC. Fisiologia Cardiovascular. In: Macari M, Furlan RL, Gonzales E. Fisiologia aviária aplicada a frangos de corte. Jaboticabal: FUNEP-UNESP; 2002. 375p.

Machado CM. Crescimento do Tecido Adiposo. In: Macari M, Furlan RL, Gonzales E. Fisiologia aviária aplicada a frangos de corte. Jaboticabal: FUNEP-UNESP; 2002. 375p.

Nagele V, Heagele OE, Sauer G, Wiedeman E, Lehmann P, Wahlefeld 
AW, Gruber WJ. Journal Clinical Chemistry Biochemistral 1984; 22(1):164-165.

NRC (National Research Council). Nutrient requirements of swine. 10th ed. Washington: National Academy Press; 1998.

Pereira FEL. Degenerações. morte celular. alterações do interstício. In: Brasileiro Filho G. Bogliolo patologia geral. Rio de Janeiro: Guanabara Koogan; 2004. 367p.

Sampietro T, Bigazzi F, Pino BD, Puntoni M, Bionda A. HDL: The new target of cardiovascular medicine. International Journal of Cardiology 2006; 108(1):143-154.

Schaefer EJ, Eisenberg S, Levy RI. Lipoprotein apoprotein metabolism. Journal Lipid Research 1978; 19(1):667-687.

Stuart NM, Bauman DE. Effect of chronic growth hormone treatment on responses to epinephrine and thyrotropin-releasing hormone in lactating cows. Journal Disease Science 1986; 69(1):44-51.

Tarlow DM, Watkins PA, Reed RE, Miller RS, Zwergel EE, Lane MD. Lipogenesis, synthesis and secretion of very low density lipoproteins by avian liver cells in non-proliferating monolayer culture. Journal Cellular Biology 1977; 73(1):332-353.

Witlock DR, Ruff MD. Comparison of the intestinal surface damage caused by Eimeria mivati, E. necatrix, E. maxima, E. brunetti and E. acervulina by scanning electron microscopy. Journal Parasitology 1977; 63(1):193-199.

Yun $\mathrm{CH}$, Lillehoj HS, Lillehoj EP. Intestinal immune responses to coccidiosis. Developmental and Comparative Imunology 2000; 24(1):303-324.

Yvore P. Effect of coccidiosis on the nutrition of the host. In: Long PL, Boorman KN, Freeman BM. Avian Coccidiosis. British Poultry Science, 1978. p.269-280. 